
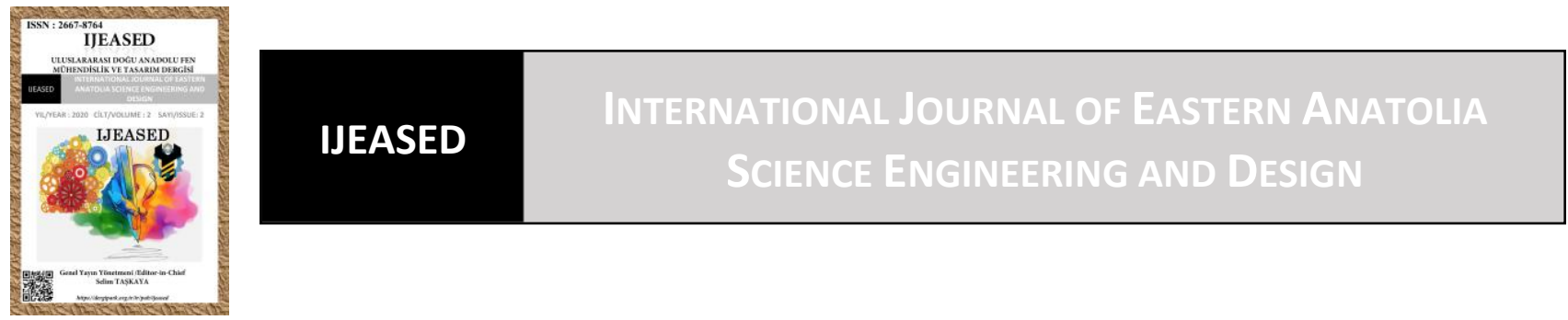

\author{
Uluslararası Doğu Anadolu Fen Mühendislik ve Tasarım Dergisi \\ ISSN: 2667-8764, 2(2), 370-379, 2020 \\ https://dergipark.org.tr/tr/pub/ijeased
}

Araştırma Makalesi / Research Article

Doi: $\underline{10.47898 / \text { ijeased.792611 }}$

\title{
Çukurova Yöresi Yapı Taşlarının Fiziksel Özellikleri Üzerine Bir Araştırma
}

\author{
Ayşe BİÇER *
}

Malatya Turgut Özal Üniversitesi, Mühendislik ve Doğa Bilimleri Fakültesi, Biyomühendislik Bölümü, Malatya, 44210, Türkiye.

\begin{tabular}{l|ll|l}
\hline \multicolumn{1}{c|}{ Yazar Kimliği / Author ID (ORCID Number) } & \multicolumn{1}{|c}{ Makale Süreci / Article Process } \\
\hline "Sorumlu Yazar / Corresponding author : & Geliş Tarihi / Received Date $:$ & 09.09 .2020 \\
ayse.bicer@ ozal.edu.tr & Revizyon Tarihi / Revision Date : & 20.11 .2020 \\
\hline iD https://orcid.org/0000-0003-4514-5644, A. Biçer & Kabul Tarihi / Accepted Date : & 22.11 .2020 \\
\hline & Yayım Tarihi / Published Date : & 15.12 .2020 \\
\hline
\end{tabular}

Alıntı / Cite : Biçer, A. (2020). Çukurova Yöresi Yapı Taşlarının Fiziksel Özellikleri Üzerine Bir Araştırma, Uluslararası Doğu Anadolu Fen Mühendislik ve Tasarım Dergisi, 2(2), 370-379.

\section{Özet}

Bu çalışmada, Adana ve yöresinde bina yapı elemanı olarak kullanılan Saimbeyli taşı, Kozan taşı, Kadirli taşı ve İçel taşları incelenmiştir. Amaç bölgede bina yapı elemanı olarak kullanılan bu taşların 1sıl ve mekanik özelliklerini araştırarak bina yapı elemanı olarak özelliklerinin belirlenmesidir. Her taş için, iki farklı ocaktan numuneler alınmış kimyasal içerikleri ve oranları belirlendikten sonra, ısıl iletkenlik, özgül ısı kapasitesi, basınç gerilmesi, su emme, teneffüs kabiliyeti ve aşınma oranları deneylerine tabi tutulmuştur. Sonuçlar, geleneksel yapı malzemeleri ile karşılaştırıldığında, taşların mekanik değerleri kabul edilebilir fakat 1sıl özellikleri yönünden zayıf olduğu görülmüştür.

Anahtar Kelimeler: Saimbeyli Taşı, Kozan Taşı, Kadirli Taşı, İçel Taşı, Yapı Malzemesi.

\section{A Research on the Physical Properties of the Building Stones in Cukurova}

\begin{abstract}
In this work, Saimbeyli, Kozan, Kadirli and Icel stones used for building materials in Adana region, are examined. The aim of this work is to determine the thermal and mechanical properties of these relevant materials on building construction. For each stone, specimens were taken from two separate localities and after the stones have been analyzed for composition and percentage of each component, heat conductivity, heat capacity, water absorption, respiration and mechanical strength measurements are carried out. The results show that all materials examined here have acceptable mechanical but poor thermal properties when compared with the conventional building materials.
\end{abstract}

Keywords: Saimbeyli Stone, Kozan Stone, Kadirli Stone, İçel Stone, Building Material. 


\section{Giriş}

Gerek enerji maliyetleri ve inşaat malzemelerindeki fiyat artışları, gerekse konut talebinin artması her bir yörenin jeolojik yapısına bağlı olarak doğal taşların taşıyıcı ve dolgu elemanı olarak kullanılmasını gündeme getirebilir. Taşlar, çoğunlukla taşıyıcı, nadiren dolgu elemanı olarak kullanılabilmiştir. Bu taşlara, Diyarbakır'ın Karaca taşı, Şanlıurfa'nın Urfa taşı, Nevşehir'in Ürgüp taşı örnek olarak gösterilebilir. Bu çalışmada, yapı malzemesi olarak kullanılabilirliği araştırılan taşların ortak özelliği, beyazımtırak kalker türlerinde olması, rezervlerinin zengin oluşu, ocaktan yeni çıkarıldığında bünyesinde bulunan nem nedeniyle, testere ile kesilebilir, matkap ile delinebilir, yontulabilir ve çivi çakılabilir durumda olmasıdır. Taşların bu özellikleri yöre halkı tarafından yapı malzemesi olarak itibar görmesini sağlamıştır. Bina yapı taşlarıyla ilgili birçok çalışma yapılmıştır. $\mathrm{Bu}$ çalışmalardan bazıları aşağıda özetlenmiştir.

Pivko (2003), taşların oluşumu ile ilgili araştırma yaparken, Türkiye'de Kazancı ve Gürbüz (2014), doğal taşlarının jeolojik oluşumları ile ilgili çalışmışlar yapmıştır. Dinçer ve diğ. (2012), ignimbiritlerin su emme oranları ile ilgili çalışma yapmıştır. Gürdal (1982), yapılarda kullanılan doğal taşların bozulma nedenleri ve korunmaları konusunu araştırmıştır. Bakış ve diğ. (2014), Ahlat Taşının inşaat sektöründe kullanılması, Bicer (2019-a) ise Ahlat ve Malazgirt taşlarının 1sıl ve mekanik özelliklerini belirleyen çalışma yapmıştır. Bicer (2019-b), yapmış olduğu farklı bir çalışmada, Fırat havzasındaki birçok yörede bina yapı malzemesi olarak kullanılan yapı taşlarının 1sıl ve mekanik özelliklerini belirlemiştir. Yine Biçer (2019-c), tarafindan yapılan bir çalışma ile Elazığ ve Nevşehir yörelerinde binalarda kullanılan yapı taşların fiziksel özellikleri ortaya konmuştur.

Bu çalışmada, Adana ve çevresinde bulunan Saimbeyli taşı, İçel taşı, Kozan taşı ve Kadirli taşı incelenerek taşların ısıl ve mekanik özellikleri belirlenmeye çalışılmıştır. Taşlar, günümüze kadar yöre halkı tarafından tercih edilmiş ve eski binalarda kullanılmıştır. Bu çalışma, taşlara uygulanan testler sonucu belirlenen özellikleri ile tercih nedenini ortaya koymaktadır.

\section{Materyal ve Metot}

\subsection{Materyal}

Çalışmada kullanılan taşların her biri yörelerinde iki farklı ocaktan temin edilmiştir. Bu taşlar ve temin yerleri aşağıda özetlenmiştir. 
Saimbeyli Taşı: Adana'nın Saimbeyli ilçesinin Doğanbeyli köyünde çıkan bu taş, mermer kalitesindedir. Büyük bloklar halinde çıkarsa mermer olarak da kullanılabilir. Saimbeyli taşı, özellikle Adana’nın yaylalarında lüks binaların yapımında kullanılmaktadır. Sertliği 6-7 mohs mertebesindedir.

Kozan Taşı: Adana'nın Kozan ilçesinin Kisenit köyünde çıkan bu taş, bina yapımında kullanıldığı gibi karo-fayans yapımında da kullanılmaktadır. Sertlik derecesi 7 mohs dur.

Kadirli Taşı: Adana'nın Kadirli ilçesinin Mazgaç yaylasında çıkmaktadır. Yöre halkı tarafından bina yapımında kullanılmaktadır. Sertliği 6-7 mohs dur.

İçel Taşı: Mersin'inin Fındık yaylasında çıkmaktadır. Genellikle cami taşı olarak kullanılan bu taş, bina yapımında da kullanılmaktadır. Ayrıca her türlü yapı elemanı olarak da kullanılma özelliğine sahiptir. Sertliği 3-4 mohs mertebesindedir.

Sedimanter oluşumlu ve karbonat bileşimli kireç taşı olan bu taşlar 1sıl deneyler için 120x50x20 mm ölçülerinde, basma gerilmesi ve aşınma oranı deneyleri için ise 100x100x100 mm ebatlarında kesilerek, yapılacak testler için hazır hale getirilmiştir (Şekil. 1).

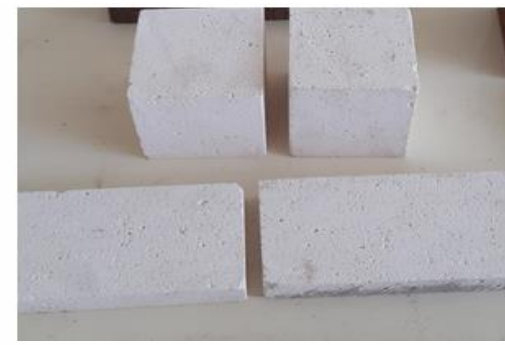

a)

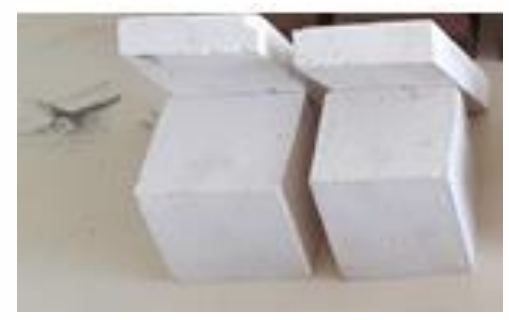

c)

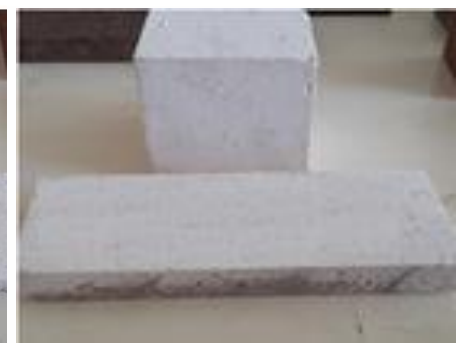

b)

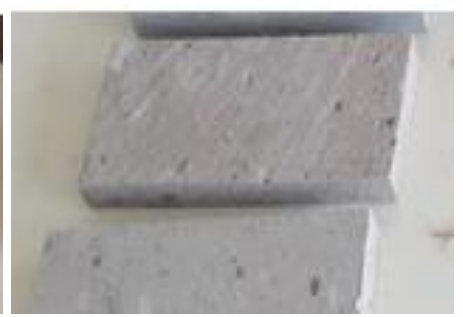

d)

Şekil. 1. Taş Örnekleri a) Saimbeyli, b) Kozan, c) Kadirli, d) İçel taş1

\subsection{Metot}

\subsubsection{Isıl iletkenlik, Özgül Isı Kapasitesi ve Isıl Yayılma}

Bu ölçümler için "Isomet 2104” marka cihaz kullanılmıştır. Cihaz, sıcak tel (Hot Wire) yöntemi ile DIN 51046 normuna göre ölçüm yapmaktadır (Isomet 2011, Vysnıauskas \& Zıkas,1988) 
Biçer, A., Uluslararası Doğu Anadolu Fen Mühendislik ve Tasarım Dergisi / International Journal of Eastern Anatolia Science Engineering and Design (IJEASED)

(2020) 2(2):370-379

(Şekil 2). Cihaz, 1sıl iletkenlik, özgül 1sı kapasitesi ve ısıl yayılma sonuçlarını birlikte vermektedir. Her numune için 3 farklı noktadan ölçümler yapılmış ve aritmetik ortalamaları alınarak Tablo 2'de topluca gösterilmiştir.

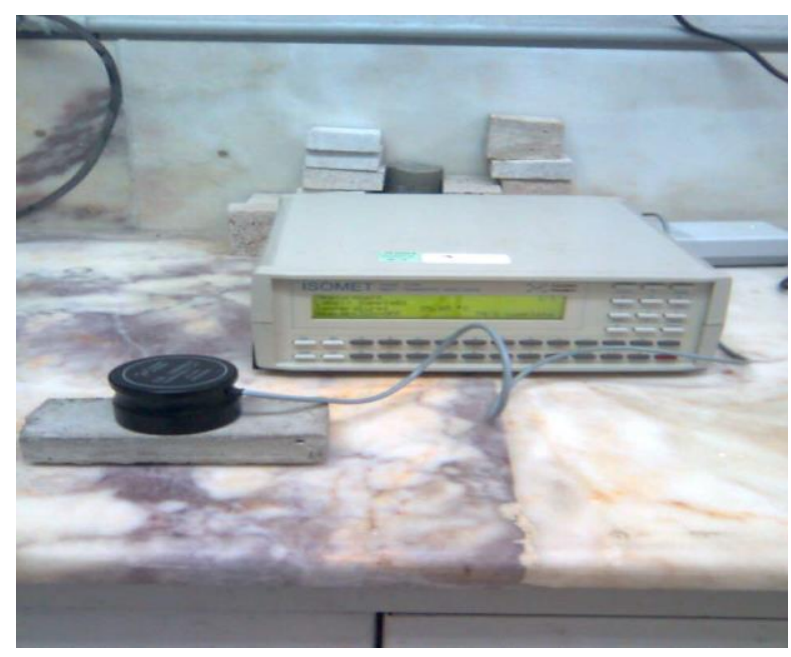

Şekil. 2. Isı1 testler için kullanılan Isomet 2104 cihazı

\subsubsection{Basınç ve Çekme Gerilmesi}

Numuneler dayanım deneyleri TS 699 standardına göre yapılmıştır. Basma gerilmesi deneylerinde, Ele International marka, $3000 \mathrm{kN}$ yüklemeli ve tek eksende kuvvet uygulayabilen cihaz kullanılmıştır (Bicer, 2019-a). Basınç dayanım sonuçları, TS 500'e göre Denklem (1) ile hesaplanarak çekme dayanım sonuçları belirlenmiştir. Sonuçlar Tablo 4'de gösterilmiştir.

$$
\mathrm{f}_{c ̧}=0.35 \times \mathrm{f}_{\mathrm{bd}}^{1 / 2}
$$

Burada, $\mathrm{f}_{\mathrm{bd}}$ : basınç dayanımı $\left(\mathrm{N} / \mathrm{mm}^{2}\right)$ ve $\mathrm{f}_{\text {çd }}$ : çekme dayanımı $\left(\mathrm{N} / \mathrm{mm}^{2}\right)^{\prime}$ dır.

\subsubsection{Aşınma Oranı Testi}

Sürtünmeden aşınma deneyi cihazı, $750 \mathrm{~mm}$ çapında aşındırma diskine sahiptir. Cihaz üzerinde devir sayısını gösteren bir gösterge vardır. Devir sayısı dijital olarak ayarlanmaktadır. Cihaz ayarlanan devri tamamladığında otomatik olarak durmaktadır (Şekil 3). Numuneler, sabitleme çenesine yerleştirilir. Çelik manivelanın bask1 kolu, numunenin üzerine bırakılır. $\mathrm{Bu}$ şekilde numunenin sabit bir kuvvet ile aşınma diskine teması sağlanır. Disk üzerine, aşınma için 20 
g zımpara tozu serpilmiştir. Her numune sonrası disk temizlenmiş ve zımpara tozu yeniden serpilmiştir.

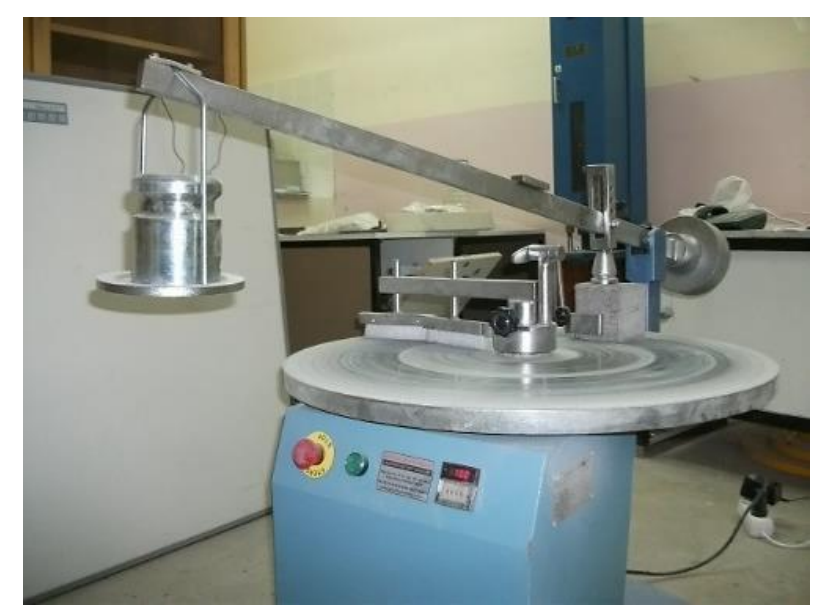

Şekil. 3. Aşınma testi cihazı

Cihaz 88 devir/dakika çalıştırılmış ve Denklem (2) lle aşınma miktarı hesaplanmıştır.

Aşınma oranı $=\left\{\left[\mathrm{W}_{1}-\mathrm{W}_{2}\right] / \mathrm{W}_{1}\right\} .100$

Burada, numunenin ilk ağırlığı, $\mathrm{W}_{1}(\mathrm{~g})$ ve son ağırlı̆̆ $\mathrm{W}_{2}(\mathrm{~g})$ dir.

\subsubsection{Su Emme Deneyi}

TSE 4045 göre yapılan bu deney, $0^{\circ} \mathrm{C}$ 'nin altındaki sıcaklıklarda ve su ile irtibatlı durumda, malzemelerin donma sonucu çatlama, parçalanma ve dağılma riskine karşı direncinin belirlenmesi amacıyla yapılmıştır. Malzemelerin su emme oranları \%30 değerin altında olması istenir (Devecioglu, 2001). Bu deney için taşların kuru ağırlığı $\left(\mathrm{W}_{\mathrm{k}}\right)$ ölçüldükten sonra. su seviyesi kademeli olarak yükseltilen bir su kabına konmuş ve numune gövdelerinin tamamı su içinde kalacak şekilde 24 saat bekletilmiştir. Sudan çıkarılıp silinerek, su emdirilmiş ağırlıkları $\left(\mathrm{W}_{\mathrm{d}}\right)$ ölçülmüş ve Denklem (3) ile su emme oranları hesaplanmıştır

Su emme oran $1=\left\{\left[\mathrm{W}_{\mathrm{d}}-\mathrm{W}_{\mathrm{k}}\right] / \mathrm{W}_{\mathrm{k}}\right\} \cdot 100$

\subsubsection{Kuruma Testi}

$\mathrm{Bu}$ deneyinin amacı, taşların teneffüs kabiliyetine sahip olup olmadığının araştırılmasıdır. Su kabından çıkarılan numuneler ıslak bir bezle silinerek $22-23{ }^{\circ} \mathrm{C}$ oda sıcaklığında doğal kuruma için 
Biçer, A., Uluslararası Doğu Anadolu Fen Mühendislik ve Tasarım Dergisi / International Journal of Eastern Anatolia Science Engineering and Design (IJEASED) (2020) 2(2):370-379

bekletilmiştir. Kuruma, suyun malzeme derinliğinden yüzeye kılcal kanallar vasıtasıyla hareketi sonucu yüzeyden buharlaşma yolu ile gerçekleşir.

\subsubsection{Yoğunluk Testi}

Hacim ölçüler belli olan taşların kuru ağırlıkları \%1 hassasiyetle ölçme yapan terazide ölçülerek, yoğunluklar hesap edilmiştir.

\section{Bulgular ve Tartışma}

Numunelerin yapılan kimyasal analiz sonuçları ile tespit edilen bileşenleri Tablo 1'de verilmiştir. Bu tablo taşların $\mathrm{CaO}$ ağırlıklı kireç taşları olduğu göstermektedir.

Tablo 1. Taşların Kimyasal Bileşimleri

\begin{tabular}{lcccc}
\hline Malzeme & $\begin{array}{c}\mathbf{S i O}_{\mathbf{2}} \\
(\boldsymbol{\%})\end{array}$ & $\begin{array}{c}\text { CaO } \\
(\boldsymbol{\%})\end{array}$ & $\begin{array}{c}\text { Kızdırma } \\
\text { kaybı (\%) }\end{array}$ & $\begin{array}{c}\text { Tayin edilemeyen } \\
(\boldsymbol{\%})\end{array}$ \\
\hline Saimbeyli taşı & 0.25 & 54.26 & 43.72 & 1.77 \\
Kozan taşı & 0.31 & 54.40 & 43.76 & 1.52 \\
Kadirli taş1 & 0.17 & 54.06 & 44.25 & 1.52 \\
İçel. taşı & 0.24 & 54.74 & 43.29 & 1.73 \\
\hline
\end{tabular}

Yöredeki çeşitli ocaklardan alınan numuneler üzerinde yapılan deneylerden, taşların yoğunluğu ortalama Saimbeyli taşı için $2640 \mathrm{Kg} / \mathrm{m}^{3}$, Kozan taşı için $2510 \mathrm{Kg} / \mathrm{m}^{3}$, Kadirli taşı için $2550 \mathrm{Kg} / \mathrm{m}^{3}$ ve İçel taşı için ise $1850 \mathrm{Kg} / \mathrm{m}^{3}$ olarak belirlenmiştir. Genellikle malzemenin porozite değeri alındıkları ocaklara göre çok az da olsa farklılık göstermektedir. Ortalama porozite değeri $\% 5$ olarak bulunmuştur.

Taş numunelerin 1sı iletim katsayıları, her bir taş üç farklı noktadan ölçülmüş ve aritmetik ortalamaları alınarak belirlenen sonuçlar Tablo 2'de topluca gösterilmiştir.

Tablo 2. Taşların Isıl Özellikleri

\begin{tabular}{|c|c|c|c|c|}
\hline Malzemeler & $\begin{array}{c}\text { Yoğunluk } \\
\left(\mathbf{k g} / \mathbf{m}^{3}\right)\end{array}$ & $\begin{array}{l}\text { Isıl iletkenlik } \\
(\mathrm{W} / \mathrm{mK})\end{array}$ & $\begin{array}{c}\text { Özgül ısı kapasitesi } \\
\text { Cp }\left(\mathrm{J} / \mathrm{kg}^{\circ} \mathrm{C}\right)\end{array}$ & $\begin{array}{l}\text { Isıl } \\
\text { yayılma } \\
\text { a.10 }^{-7}\left(\mathrm{~m}^{2} / \mathbf{s}\right)\end{array}$ \\
\hline Saimbeyli taşı & 2640 & 2.13 & 948 & 8.5 \\
\hline Kozan taşı & 2510 & 1.84 & 832 & 8.8 \\
\hline Kadirli taş1 & 2550 & 1.86 & 802 & 9.1 \\
\hline İçel. taş1 & 1850 & 1.2 & 798 & 8.1 \\
\hline
\end{tabular}

Belirlenen bu sonuçlar, diğer yapı malzemelerin fiziksel verileri ile çeşitli yönlerden kıyaslanmıştır. Gerek sürekli ve gerekse zamana bağlı rejimde 1sı transferi göz önüne alındığında, Saimbeyli taşı, 1sıl iletkenlik yönünden Tablo 3'de gösterilen malzemelerden mermere göre daha iyi 
görünmektedir. Kozan taşı ve Kadirli taşının 1sı iletim katsayısı ise granit ve kum taşına göre yaklaşık aynı değerlerde olup mermerden daha küçüktür. Buna karşılık İçel taşı $1.2 \mathrm{~W} / \mathrm{mK}$ değeri ile granit, mermer ve kum taşına göre 1sıl iletkenlik değeri daha küçüktür. Taşların özgül 1sı kapasiteleri Tablo 3' gösterilen yapı malzemelerine yakın olmasına karşılık ısıl yayılmaları granit ve kum taşına göre daha düşük çıkmıştır. Taşların gerek özgül 1sı kapasitesi ve gerekse ısıl yayılma değerleri birlikte değerlendirilmesi halinde, bu taşların kullanıldığı binalarda gece ve gündüz sıcaklık farkından kaynaklanan konfor rahatlığı sağlanmaktadır. Taşın bu özelliğinin yanında birçok yapı elemanına kıyasla kolayca işlenebilmesi, elektrik ve su tesisatı kanalları açmak amacıyla delinebilmesi, kesilebilmesi, çivi ve vida kullanımına izin vermesi kullanılabilirlik bakımından büyük avantajdır.

Tablo 3. Bazı Yapı Malzemelerin Isı1 Özellikleri (Toksoy,1988)

\begin{tabular}{|c|c|c|c|c|}
\hline Malzemeler & $\begin{array}{c}\text { Yoğunluk } \\
\left(\mathbf{k g} / \mathbf{m}^{3}\right)\end{array}$ & $\begin{array}{l}\text { Isıl iletkenlik } \\
\qquad(\mathrm{W} / \mathrm{mK})\end{array}$ & $\begin{array}{c}\text { Özgül ısı kapasitesi } \\
\mathrm{Cp}\left(\mathrm{J} / \mathrm{kg}^{\circ} \mathrm{C}\right)\end{array}$ & $\begin{array}{l}\text { Isıl } \\
\text { yayılma } \\
\text { a.10 } 10^{-7}\left(\mathrm{~m}^{2} / \mathrm{s}\right)\end{array}$ \\
\hline Beton & 1906 & 0.814 & 879 & 4.91 \\
\hline Granit & 2643 & 1.73 & 816 & 13.15 \\
\hline Kalker & 2483 & 1.16 & 906 & 5.68 \\
\hline Kum taşı & 2235 & 1.85 & 712 & 11.65 \\
\hline Mermer & 2603 & 2.77 & 808 & 3.94 \\
\hline Tuğla & 1602 & 0.692 & 837 & 5.16 \\
\hline
\end{tabular}

Bunların yanında, incelenen taşlar içerisinde, Saimbeyli ve Kadirli taşları Tablo 4'de gösterilen tek eksenli basınç gerilmesi değerleri olan $21 \mathrm{~N} / \mathrm{mm}^{2}$ lik ve $16 \mathrm{~N} / \mathrm{mm}^{2}$ ile daha iyi durumdadır. Bu taşların yük taşıyıcı duvar ve bölme elemanı olarak kullanılmasının yanında, hesaplanan \%0.6 ve \%0.7' lik aşınma kaybı değerleri ile merdiven, parke gibi fazla aşınmaya maruz yapı elemanı olarak da kullanılabileceğini gösterir. Kozan ve İçel taşları dayanım değerleri yüksek olmamasına karşılık, taşların maliyetlerinin düşük olması ve özellikle İçel taşının hem taşıyıcı hem de enerji tasarrufu yönünden dış duvarlarda tuğla ve briket gibi kullanılması tercih nedeni olmaktadir.

Tablo 4. Taşların Mekanik Özellikleri

\begin{tabular}{lcccc}
\hline Malzemeler & $\begin{array}{c}\text { Basma } \\
\text { gerilmesi } \\
\left(\mathbf{N} / \mathbf{m m}^{\mathbf{2}}\right)\end{array}$ & $\begin{array}{c}\text { Çekme } \\
\text { gerilmesi } \\
\left(\mathbf{N} / \mathbf{m m}^{\mathbf{2}}\right)\end{array}$ & $\begin{array}{c}\text { Su emme } \\
\text { oranı } \\
(\boldsymbol{\%})\end{array}$ & $\begin{array}{c}\text { Aşınma } \\
\text { oranı } \\
(\boldsymbol{\%})\end{array}$ \\
\hline Saimbeyli taş1 & 21 & 2.0 & 16 & 0.6 \\
Kozan taş1 & 12.5 & 1.1 & 13 & 2.5 \\
Kadirli taş1 & 16 & 1.5 & 18 & 0.7 \\
Icel. taş1 & 6.5 & 0.6 & 14 & 4.9 \\
\hline
\end{tabular}

Su emme ve kuruma deneylerinde, incelenen taşların tamamının su emme oranı \%30'dan küçük çıkmıştır. $\mathrm{Bu}$ nedenle $0^{\circ} \mathrm{C}$ altındaki sıcaklıklarda donma yönünden hiç biri tehlike arz 
Biçer, A., Uluslararası Doğu Anadolu Fen Mühendislik ve Tasarım Dergisi / International Journal of Eastern Anatolia Science Engineering and Design (IJEASED)

(2020) 2(2):370-379

etmemekte olup bu özellik taşların nemli ortamlarda kullanılabileceğini göstermektedir. Su emme deneyinde numunelerin zamana göre ağırlık değişimi Şekil 5'de gösterilmiştir. Kuruma deneyinde ise taşların zamana göre ağırlık değişimi Şekil 6'da gösterilirken, azda olsa teneffüs kabiliyetine sahip oldukları görülmektedir (Şekil 6).

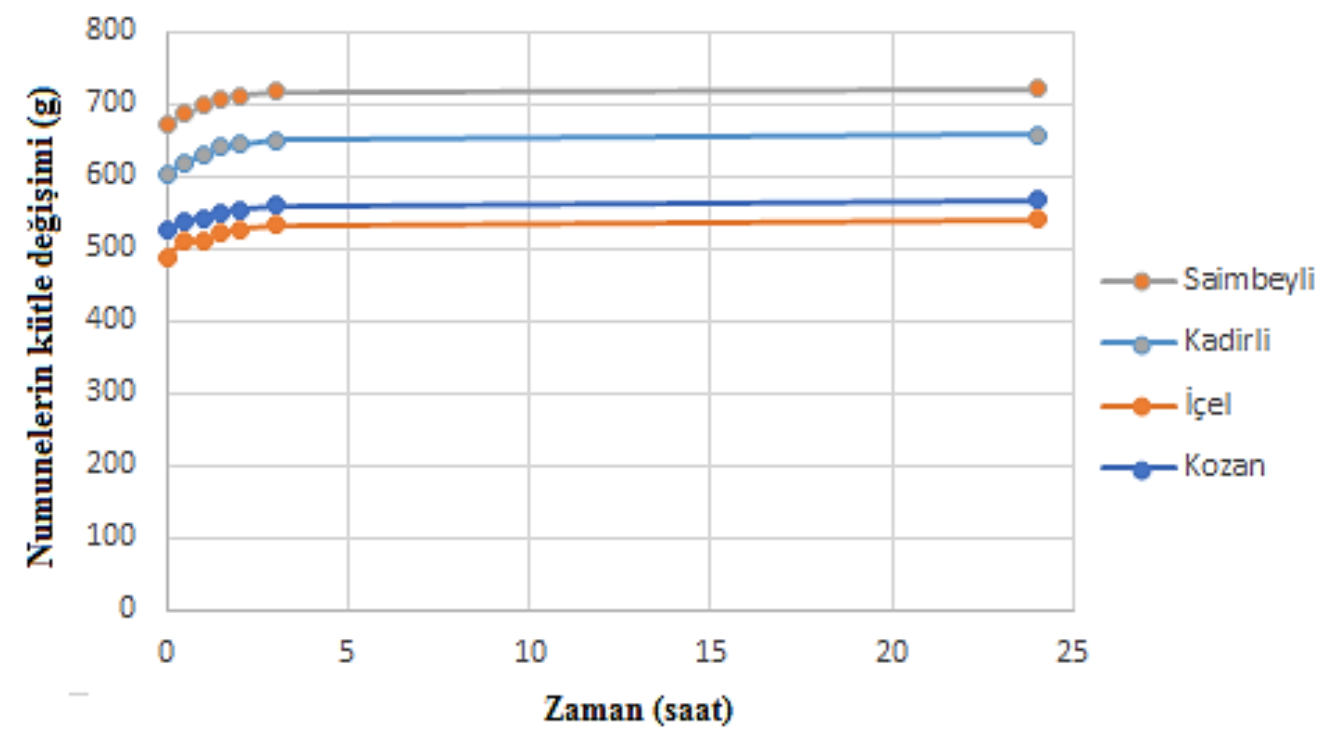

Şekil 5. Taşların Su Emme Deneyinde Zamana Göre Kütle Değişimi

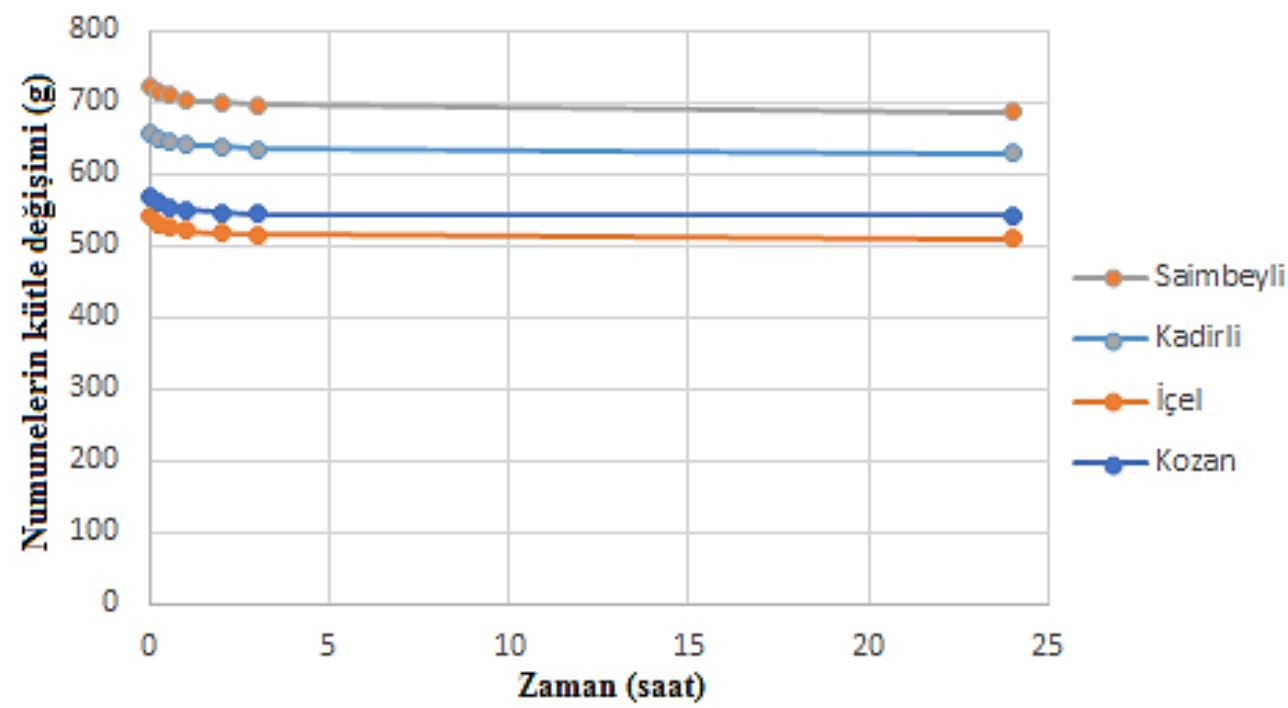

Şekil 6. Taşların Kuruma Deneyinde Zamana Göre Kütle Değişimi 


\section{Sonuçlar}

Adana ve İçel şehirlerinin merkez ve ilçelerinde bina yapı elemanı olarak kullanılan yöre taşlarının 1sıl ve mekanik özellikleri deneysel olarak incelenmiş ve sonuçlar aşağıda verilmiştir.

$\checkmark$ İçel taşının düşük 1sı iletim katsayısına sahip olması nedeniyle $(1.2 \mathrm{~W} / \mathrm{mK})$ bina dış duvarlarında tuğla yerine kullanılması enerji ekonomisi yönünden önemlidir. İncelenen diğer taşların 1sıl özellikleri enerji ekonomisi yönünden cazip görünmemektedir.

$\checkmark$ İncelenen taşlar içerisinde, özelikle Saimbeyli taşı $\left(21 \mathrm{~N} / \mathrm{mm}^{2}\right.$ basınç gerilmesi, \% 0.6 aşınma oranı), Kadirli taşı $\left(16 \mathrm{~N} / \mathrm{mm}^{2}\right.$ basınç gerilmesi, \% 0.7 aşınma oranı) ve Kozan taşı $\left(12.5 \mathrm{~N} / \mathrm{mm}^{2}\right.$ basınç gerilmesi) belirlenen değerleriyle, yük taşıyıcı duvar malzemelerinin yanı sıra aşınmaya dayanıklı döşeme kaplaması malzemesi olarak da kullanılabileceğini göstermektedir.

$\checkmark$ İncelenen taşların, ocaklarının zengin rezervlere sahip olması, temini, işlenmelerinin kolay olması ve kesilerek doğrudan tuğla veya briket yerine kullanılması nedeniyle maliyetinin ucuz olmasi tercih nedeni olarak kabul edilebilir.

\section{Kaynaklar}

Bakış A, Işık E, Hattatoğlu F. Akıllı A., (2014). Jeolojik miras nitelikli Ahlat Taşı'nın inşaat sektöründe kullanımı, III. Uluslararası Ahlat-Avrasya Bilim, Kültür ve Sanat Sempozyumu Bildiriler Kitabı (Editörler Doğru M. ve Aksoy E.), 46-59, 22-24 Eylül Ahlat- Bitlis.

Biçer A., (2019-a). Ahlat ve Malazgirt yapı taşlarının bazı fiziksel özellikleri, Fırat Üniversitesi Müh. Bil. Dergisi, 31(2), 301-307.

Bicer A., (2019-b). Some physical properties of the building Stones from southeastern Anatolia region, Bartın University International Journal of Natural and Applied Sciences, 2(1), 9-15.

Bicer A., (2019-c). Some physical properties of the building stones from Elazıg-Nevsehir region, Nevşehir Bilim ve Teknoloji Dergisi, 8(2), 96-102.

Bicer A, (2019-d), Influence of tragacanth resin on the thermal and mechanical properties of fly ash-cement composites, Journal of Adhesion Science and technology, 33(10), 1019-1032.

Devecioglu A.G. (2001), An investigation on the heat conduction parameters of porous building stones, $Y$. Lisans Tezi, Firat Universitesi.

Dinçer İ, Özvan A., Akın, M., Tapan, M., Oyan, V., (2012). İgnimbiritlerin kapiler su emme potansiyellerinin değerlendirilmesi: Ahlat Taşı örneği. Yüzüncü Yll Üniversitesi Fen Bilimleri Enstitüsü Dergisi, 17 (2), 64-71, 2012.

Gürdal E., (1982). Anıtlarda ve yapılarda kullanılmış doğal taşların bozulmaları ve korunmaları, Rölöve ve Restorasyon Dergisi, 27-33.

Isomet 2104, (2011), Applied Precision Ltd, Instrument products department, Bratislava-Slovakia.

Kazanc1 N, Gürbüz A., (2014). Jeolojik miras nitelikli Türkiye doğal taşları, Türkiye Jeoloji Bülteni, 57: 1.

Pivko D., (2003), Natural stones in earth's history, Acta Geologica, 58, 73-86. 
Biçer, A., Uluslararası Doğu Anadolu Fen Mühendislik ve Tasarım Dergisi / International Journal of Eastern Anatolia Science Engineering and Design (IJEASED)

(2020) 2(2):370-379

Toksoy M. (1988), Thermal conductivity coefficients of industrial materials, Journal of Engineers and Machinery, 347, 12-15.

TS 699/T1, (2016). Doğal yapı taşları - İnceleme ve laboratuvar deney yöntemleri, TSE, Ankara.

TSE 500, (2000), TSE, Ankara.

TSE 4045 (1984)-Yapı malzemelerinde kapiler su emme tayini TSE, Ankara.

Vysniauskas V.V, Zikas A.A. (1988), Determination of the thermal conductivity of ceramics by the HotWire Technique. Heat Transfer Soviet Research, 20 (1): 137-142. 